\title{
Bacteria bioburden assessment and MRSA colonization of workers and animals from a Portuguese swine production: A case report
}

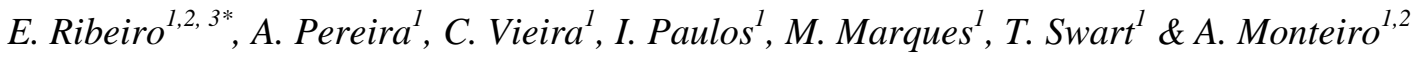 \\ ${ }^{I}$ Escola Superior de Tecnologia da Saúde de Lisboa, ESTeSL, Instituto Politécnico de Lisboa, Av. D. João II, Lote \\ 4.69.01, 1990-096 Lisboa, Portugal
}

${ }^{2}$ Environment and Health Research Group, Escola Superior de Tecnologia da Saúde de Lisboa, ESTeSL, Instituto Politécnico de Lisboa, Av. D. João II, Lote 4.69.01, 1990-096 Lisboa, Portugal;

${ }^{3}$ Research Center LEAF - Linking Landscape, Environment, Agriculture and Food - Instituto Superior de Agronomia, Universidade de Lisboa, Portugal

ABSTRACT: Pigs are important reservoir of livestock-associated bacteria, including methicillin-resistant staphylococcus aureus (MRSA), which constitute a professional hazard for workers in direct contact with these animals with increased risk of nasal colonization, potentially associated with subsequent clinical diseases and transference of the infection to others.

Here we performed a bioburden characterization concerning bacterial prevalence and resistance (MRSA) in workers and animals from a Portuguese swine production as a case study.

Air samples were collected through an impaction method. Biological samples were obtained through nasopharyngeal swab procedure. Identification of $S$. aureus was performed trough immunologic tests.

We report an exceedingly high prevalence of total bacteria and S.aureus colonization (100\%) in workers and animals whereas all of identified strains were MRSA. Additionally, air samples demonstrated high values of total bacterial concentration.

This work raises awareness to the relevance of bioburden monitoring and the requirement to create occupational standards and take effective preventive measures.

\section{INTRODUCTION}

The World Health Organization (WHO) describes antimicrobial resistance to human pathogens as a global health challenge (World Health Organization (WHO) 2016). Currently, it is acknowledged that the extensive use of antibiotics are the driving force for the worldwide escalation of these microorganisms (Morris \& Masterton 2002). For the past decades the amount of large animal-feeding operations (AFOs) including swine, has increased expressively (UEFSA 2001) and a large variety of feed additives and drugs, particularly antibiotics, are approved for use in food-animal agriculture (Bloom 2004). Antibiotics are extensively utilized in the management of animal health, and more recently to growth enhancement and feed efficiency in healthy livestock, which may result in an antibiotic selection pressure responsible for the emergence of resistant strains in these contexts. Although, it is largely assumed that resistant strains such as methicillin-resistant staphylococcus aureus (MRSA) originated in humans, the emergence of the first pig-associated strain (ST398) (Armand-Lefevre et al. 2005), which in very few years spread worldwide into diverse livestock species, corroborates this hypothesis.

Currently, animals such as pigs are important reservoir of livestock-associated clones of MRSA (LAMRSA) which in addition to the animal to animal spread one of the early features of these strains was its ability to transfer from pigs to humans (Barton
2014). Consequently, for workers that spend several daily hours in direct contact with MRSA positive animals, MRSA colonization is a patent and significant professional hazard (Denis et al. 2009; Moodley et al. 2008). MRSA carriers have increased risk for subsequent clinical associated diseases and become a bacterial reservoir with associated high risk to transfer the infection to others, including household members (Hatcher et al. 2016), and to contaminate foods and food surfaces during handling (Jordan et al. 2011). Although MRSA infections are wellknown worldwide as a cause of numerous hospitalizations and deaths associated with extremely high mortality rates for invasive infections (Klevens et al. 2007), exposure assessment procedures in occupational environments are not adapted to animal production settings, although swine confinement buildings have been placed among the working environments with the highest bioaerosol (Donham et al. 1989). Thus it is imperative to perform a real scenario characterization concerning bacterial prevalence and resistance in order to avoid health hazardous effects in workers and animals, particularly in swine productions.

In the European context, colonization by LA-MRSA have become, in the past years, an exceedingly debated topic particularly in the context of occupational exposure (Goerge et al. 2015), and in Portugal, a recent study also demonstrates the substantial establishment of ST398-MRSA among healthy pigs in swine farms. 
In this work we aimed to perform a bioburden characterization of occupational exposure to bacteria through environmental sampling in swine facilities, microbiota prevalence and antimicrobial resistance, namely MRSA prevalence, in animals and workers of a Portuguese swine production.

\section{MATERIALS AND METHODS}

Study population: The study included all the pigfarm workers $(n=3)$, which provided a signed written informed consent before enrolment in the study. The studied animals were in the stalls and had with 3 weeks old $(n=15)$.

Collection, isolation and microbiological procedures Biological samples were obtained through nasopharyngeal swab procedure using transport swabs with Stuart media, and immediately transported to the laboratory. In the microbiology laboratory samples were cultured in Columbia agar with 5\% sheep blood, for MRSA identification, and incubated for 24 hours at $37^{\circ} \mathrm{C}$. Tryptic soy agar (TSA) supplemented with nystatin $(0.2 \%)$ for mesophilic bacterial population and violet red bile agar (VRBA) for bacteria belonging to the Enterobacteriaceae family (e.g. coliforms - Gram-negative bacteria). TSA and VRBA plates were incubated at $30^{\circ} \mathrm{C}$ and $35^{\circ} \mathrm{C}$ for 7 days, respectively. After the incubation period, quantitative colony-forming were obtained, colonies were evaluated based on cultural characteristics and S.aureus suspicious colonies isolated and incubated for 24 hours at $37^{\circ} \mathrm{C}$. Identification of $S$. aureus was performed trough catalase test and Slidex Staph Kit (Biomerieux ref \#73115). MRSA strains were identified through Slidex MRSA detection Test Kit (Biomerieux ref \#73117). In this work positive (S. aureus MRSA laboratory collection) and negative (S. aureus ATCC 25923) control strains will be included as positive and negative controls.

Air samples of $50 \mathrm{~L}$ were collected through an impaction method with a flow rate of $140 \mathrm{~L} / \mathrm{min}$ (Millipore air Tester, Millipore, Billerica, MA, USA) onto each media plate. TSA supplemented with nystatin $(0.2 \%)$ and VRBA were used in order to enhance the selectivity for bacterial populations growth and incubated at $30^{\circ} \mathrm{C}$ and $35^{\circ} \mathrm{C}$ for 7 days, respectively. After laboratory processing and incubation of the samples, quantitative colony-forming were obtained (colony-forming units - CFU.m ${ }^{-3}$ ).

The five sampling sites in gestation, maternity, stalls, fattening and quarantine from the studies swine production were selected based on the higher daily exposure of workers to animals. Outdoor samples were also performed to be used as reference.

\section{RESULTS}

In all biological samples collected from workers normal commensal flora, namely staphylococcus spp. and streptococcus spp. was observed. Moreover, sample analysis also demonstrated a frequency of 3 in 3 (100\% prevalence) of total bacterial load. One worker showed countless mesophilic bacteria, and no Gram-negative bacteria isolates were detected.

In animals, we also identified 15 in 15 frequencies (100\% prevalence) of total bacterial load and two swine samples showed countless mesophilic bacteria. Gram-negative bacteria analysis resulted in a frequency of 11 in 15 (73,3\% prevalence) individuals, one animal showed countless coliforms and in four animals no isolates were observed (Table 1).

Table 1. Frequency analysis of total bacteria and gram-negative bacteria carriers amongst livestock occupational exposed individuals and animals.

\begin{tabular}{cccc}
\hline Individuals & Swabs & $\begin{array}{c}\text { Total bacteria } \\
\text { frequency analysis }\end{array}$ & $\begin{array}{c}\text { Gram-negative bacteria } \\
\text { frequency analysis }\end{array}$ \\
\hline Workers & 3 & 3 in 3 & 0 in 3 \\
\hline Piglets & 15 & 15 in 15 & 11 in 15 \\
\hline
\end{tabular}

The frequency analysis of $S$. aureus in workers of the studied swine production demonstrated a 3 in 3 (100\% prevalence) colonization occurrence. Regarding the resistance profile, all $S$. aureus strains were resistant to methicillin (MRSA). Additionally, all animals analyzed were also colonized by MRSA. These results are summarized in table 2 .

Table 2. Frequency analysis of S.aureus and MRSA carriers amongst livestock occupational exposed individuals and animals.

\begin{tabular}{cccc}
\hline Individuals & Swabs & $\begin{array}{c}\text { S.aureus frequency } \\
\text { analysis }\end{array}$ & $\begin{array}{c}\text { MRSA frequency } \\
\text { analysis }\end{array}$ \\
\hline Workers & 3 & 3 in 3 & 3 in 3 \\
\hline Piglets & 15 & 15 in 15 & 15 in 15 \\
\hline
\end{tabular}

Total air bacterial load ranged from $5360 \mathrm{CFU} \cdot \mathrm{m}^{-3}$ to 18260 CFU.m ${ }^{-3}$ (median 11944 CFU.m ${ }^{-3}$ (Figure 1). Airborne coliforms load only grow up in one sampling site (gestation with 20 CFU.m ${ }^{-3}$ ).

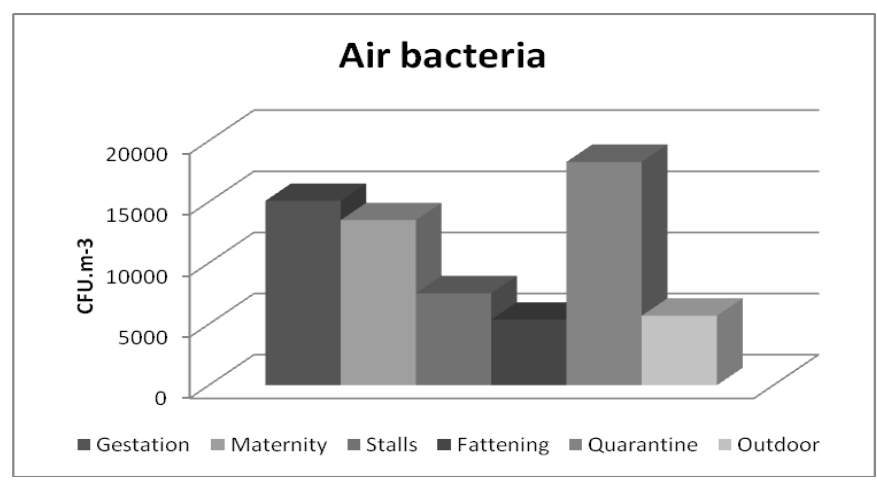

Figure 1 - Bacterial load obtained on air samples 


\section{DISCUSSION}

Bacteria bioburden is a key component of bioaerosols which may occur as solid or liquid particles in the air. Prolonged exposure to bioaerosols particularly at workplaces can represent a health hazard (Walser et al. 2015) for workers and for the spread of these microorganisms in the community. For the past years, numerous studies have increased scientific data on occupational exposure to bioaerosols and helped to understand the relationship between exposure and health effects (Ghosh Lal and Srivastava, 2015).

In the context of animal production, it is acknowledged that animals, such as pigs, are important reservoir of livestock-associated bacteria with associated resistances to antibiotics, including LA-MRSA (Armand-Lefevre et al. 2005). Considering that $S$. aureus can colonize the human nostrils via simple inhalation of contaminated air (Masclaux et al. 2013), the direct contact with live animal carriers is possibly the main route of human exposure to bacterial strains such as LA-MRSA. Moreover, LAMRSA transmission between pig farms mainly occurs through animal trade and to a minor level via humans or livestock transportation (Leibler et al. 2016; Grøntvedt et al. 2016). Nasal LA-MRSA colonization rates in pig farmers is maintained at $59 \%$ after time periods with no occupational exposure (holidays) (Köck et al. 2012) indicating that persistent MRSA colonization is expected to be more probable in occupationally exposed individuals (Goerge et al. 2015).

Although there are no national guidelines to impose limit values for airborne bacteria load, some studies (Goyer 2001) were carried out to propose guidelines for eight hours of work indicating 10000 CFU.m ${ }^{-3}$ for total bacteria and 1000 CFU.m ${ }^{-3}$ for Gramnegative bacteria in agricultural and industrial environments.

Here we demonstrated that the majority of the collected air samples presented higher values of total airborne bacterial. The high concentrations of total bacteria instead of airborne coliform could be explained by the fact that $90 \%$ of the bacteria isolated from the feces of adult swine are reported as gram positive (Salanitro et al. 1977). The higher concentration of airborne bacteria indoor when compared to the outdoor, suggests that the outdoor air quality can be influenced by the sources of contamination of this activity.

Animal-to-human transmission during farming has been already demonstrated for enterobacteria and enterococci (Armand-Lefevre et al. 2005) and our results suggest that type of transmission can happen, particularly since virtually no protection were used by the workers.

Regarding bacteria identification, we reported concerning high colonization levels of MRSA, both in workers and in animals, as all analyzed individuals were carriers. These levels are exceedingly higher than levels detected in the community for S.aureus $(31 \%)$ and for MRSA (2\% - 3\%) (Hatcher et al. 2016) and in other Portuguese swine productions (Conceição et al. 2017). Considering that, human MRSA carriers prevalence is higher in intensive antibiotic-using piggeries when compared to antibioticfree which indicate that antibiotic use is a driver for worker colonization (Rinsky et al. 2013), it would be important to asses antibiotic use in the studied swine production. Moreover, it is also important to notice that occupational exposure to LA-MRSA not only constitutes an important professional hazard but also constitute a relevant risk to individuals that came direct in contact with exposed workers, particularly children that have high colonization prevalence when the worker is a carrier (Hatcher et al. 2016), which represents a public health concern. Additionally, although most of LA-MRSA have been isolated form healthy animals some strains were also isolated from pathological lesions in pigs (Pomba et al. 2009), thus our results may also indicate some concern for animal health.

\section{CONCLUSIONS}

This work raise the awareness of the urgent need to monitor MRSA strains associated with animal carriers, occupational exposed individuals and potential sources of environmental contamination. Valuable and effective efforts must be made to create occupational health surveillance programs and to determine and regulate the antibiotic selection pressure that is driving the emergence of these strains.

\section{AKNOWLDEGEMENTS}

This work was funded by Concurso Anual para Projetos de Investigação, Desenvolvimento, Inovação e Criação Artística (IDI\&CA) do IPL - 2016, BBIORHealth "Bacterial Bioburden assessment in the context of occupational exposure and animal health of swine productions" Edna Ribeiro - Escola Superior de Tecnologia da Saúde de Lisboa

\section{REFERENCES}

Armand-Lefevre, L., Ruimy, R. \& Andremont, A., 2005. Clonal comparison of Staphylococcus from healthy pig farmers, human controls, and pigs. Emerging Infectious Diseases, 11(5), pp.711-714.

Barton, M.D., 2014. Impact of antibiotic use in the swine industry. Current Opinion in Microbiology, 19(1), pp.9-15. Available at: http://dx.doi.org/10.1016/j.mib.2014.05.017. 
Bloom, R.A., 2004. Use of veterinary pharmaceuticals in the United States. In Pharmaceuticals in the Environment. Springer, pp. 149-154.

Conceição, T., De Lencastre, H. \& Aires-De-Sousa, M., 2017. Frequent isolation of methicillin resistant Staphylococcus aureus (MRSA) ST398 among healthy pigs in Portugal. PLoS ONE, 12(4), pp.1-7.

Denis, O. et al., 2009. Methicillin-resistant Staphylococcus aureus ST398 in swine farm personnel, Belgium. Emerging Infectious Diseases, 15(7), pp.1098-1101.

Donham, K. et al., 1989. Environmental and health studies of farm workers in Swedish swine confinement buildings. British journal of industrial medicine, 46(1), pp.31-37.

Ghosh, B., Lal, H. \& Srivastava, A., 2015. Review of bioaerosols in indoor environment with special reference to sampling, analysis and control mechanisms. Environment International, 85, pp.254-272. Available at: http://dx.doi.org/10.1016/j.envint.2015.09.018.

Goerge, T. et al., 2015. MRSA colonization and infection among persons with occupational livestock exposure in Europe: Prevalence, preventive options and evidence. Veterinary Microbiology. Available at: http://dx.doi.org/10.1016/j.vetmic.2015.10.027.

Goyer, N., 2001. Les bioaérosols en milieu de travail,

Grøntvedt, C.A. et al., 2016. Methicillin-Resistant Staphylococcus aureus CC398 in Humans and Pigs in Norway: A \&quot;One Health\&quot; Perspective on Introduction and Transmission. Clinical infectious diseases: an official publication of the Infectious Diseases Society of America, 63, p.ciw552. Available at: http://www.ncbi.nlm.nih.gov/pubmed/2751638 1.

Hatcher, S.M. et al., 2016. The Prevalence of Antibiotic-Resistant Staphylococcus aureus Nasal Carriage among Industrial Hog Operation Workers, Community Residents, and Children Living in Their Households: North Carolina, USA. Environmental health perspectives, (October). Available at: http://www.ncbi.nlm.nih.gov/pubmed/2775342 9.

Jordan, D. et al., 2011. Carriage of methicillinresistant Staphylococcus aureus by veterinarians in Australia. Australian Veterinary Journal, 89(5), pp.152-159.

Klevens RM, Morrison MA, Nadle J, Petit S, Gershman K, Ray S, Harrison LH, Lynfield R, Dumyati G, Townes JM, Craig AS, Zell ER, Fosheim GE, McDougal LK, Carey RB, F.S.A.B.C. surveillance (ABCs) M.I., 2007. Invasive methicillin-resistant Staphylococcus aureus infections in the United States. JAMA, 298(15), pp.1763-71.

Köck, R. et al., 2012. Persistence of nasal colonization with livestock-associated methicillin-resistant staphylococcus aureus in pig farmers after holidays from pig exposure. Applied and Environmental Microbiology, 78(11), pp.4046-4047.

Leibler, J.H. et al., 2016. Staphylococcus aureus nasal carriage among beefpacking workers in a Midwestern United States slaughterhouse. PLoS ONE, 11(2), pp.1-11.

Masclaux, F.G. et al., 2013. Concentration of airborne staphylococcus aureus (MRSA and MSSA), total bacteria, and endotoxins in pig farms. Annals of Occupational Hygiene, 57(5), pp.550-557.

Moodley, A. et al., 2008. High risk for nasal carriage of methicillin-resistant Staphylococcus aureus among Danish veterinary practitioners. Scandinavian Journal of Work, Environment and Health, 34(2), pp.151-157.

Morris, A.K. \& Masterton, R.G., 2002. Antibiotic resistance surveillance: action for international studies. The Journal of antimicrobial chemotherapy, 49(1), pp.7-10. Available at: http://www.ncbi.nlm.nih.gov/pubmed/1175175 9.

Pomba, C. et al., 2009. First description of meticillin-resistant Staphylococcus aureus (MRSA) CC30 and CC398 from swine in Portugal. International Journal of Antimicrobial Agents, 34(2), pp.193-194.

Rinsky, J.L. et al., 2013. Livestock-Associated Methicillin and Multidrug Resistant Staphylococcus aureus Is Present among Industrial, Not Antibiotic-Free Livestock Operation Workers in North Carolina. PLoS ONE, 8(7), pp.1-11.

Salanitro, J.P., Blake, I.G. \& Muirhead, P.A., 1977. Isolation and identification of fecal bacteria from adult swine. Applied and Environmental Microbiology, 33(1), pp.79-84.

UEFSA, 2001. Development document for the proposed revisions to the national pollutant discharge elimination system regulation and the effluent guidelines for concentrated animal feeding operations. Washington: EPA.

Walser, S.M. et al., 2015. Evaluation of exposureresponse relationships for health effects of microbial bioaerosols - A systematic review. International Journal of Hygiene and Environmental Health, 218(7), pp.577-589. Available at: http://dx.doi.org/10.1016/j.ijheh.2015.07.004.

World Health Organization (WHO), 2016. Antimicrobial resistance: fact sheet $n^{0} 194$. Genebra: WHO. Available at: http://www.who.int/mediacentre/factsheets/fs 19 4/en/ [Accessed June 20, 2012]. 